\section{Interpedal generalization of rearranged eye-foot coordination*}

\author{
H. H. MIKAELIAN \\ Connecticut College, New London, Conn. 06320
}

Self-produced movements of one leg viewed through wedge prisms produce adaptive changes in eye-foot coordination that transfer to the unexposed leg. Results of a second experiment show that eye-hand coordinations, entailing the arm ipsilateral as well as contralateral to the leg whose movements were viewed through prisms, also manifest corresponding adaptive changes.

Walking while wearing prisms, or simply moving the leg while viewing it through prisms, produces corrective changes not only in eye-foot coordination, but also in gross perceptual orientation (egocentric localization) and in eye-hand coordination. Prism-viewed arm movements, however, have been shown to modify only eye-hand coordination (Hamilton, 1964a; Mikaelian, 1970). Furthermore, under certain conditions, prism-viewed arm movements generate adaptation only for the arm viewed (Harris, 1963; Mikaelian, 1963; Hamilton, 1964a).

It is clear, therefore, that during optical rearrangement, arm movements and leg movements act as distinctly different sources of feedback, despite the fact that both are limb movements. Prism-displaced visual information originating from leg movements apparently produces generalized adaptation. In contrast to sensorimotor changes produced by arm movements, adaptation produced by leg movements, therefore, should transfer interpedally. Additionally, eye-hand responses, entailing both the arm ipsilateral and contralateral to the leg viewed through prisms, should also manifest these adaptive changes. Two experiments were designed to test these predictions and explore Hamilton's (1964b) findings of these generalized transfers.

\section{APPARATUS}

The apparatus included an eye-foot exposure table, an eye-foot coordination test box, and an eye-hand coordination test box. The exposure apparatus consisted of prism goggles (20 diopter wedge prisms producing $10 \mathrm{deg}$ of lateral displacement of the visual field) mounted over a rectangular opening on a slanted tabletop. It allowed $\mathrm{S}$ to view his leg movements by resting his head on the goggles and moving his leg under the tabletop (only one leg visible). The eye-foot and eye-hand coordination test boxes were Held-Gottlieb (1958) test box. These were built to allow $S$ to view a mirror which, at $45 \mathrm{deg}$ to the plane of the targets, made the targets appear to lie on a horizontal surface upon which he marked (with the arm or the foot) the perceived location of the targets. Details of the apparatus are given in an earlier paper (Mikaelian, 1970).

\section{PROCEDURE}

Experiment 1

(Interpedal Transfer)

Following preexposure measures of eye-foot coordination (four targets presented singly in a random order were marked eight times each for a total of 32 markings), first with one leg and then the other, each of 12 Ss viewed his leg movements through prisms for $50 \mathrm{~min}$. Six of the Ss viewed through base-left and the other six through base-right prisms. The order of the leg viewed was counterbalanced. Postexposure measures of eye-foot coordination were taken first with the contralateral essentially a modification of the and then the ipsilateral leg. Experiment 2

(Interlimb Transfer)

Following preexposure measures of eye-foot coordination with the right foot, and of eye-hand coordination first with one arm and then the other, each of eight Ss (different from Experiment 1) viewed the movements of his right leg through base-left prisms for $30 \mathrm{~min}$. (Prism base-left right-foot rearrangement condition was chosen for Experiment 2 because the results of Experiment 1 showed that to be the most effective for producing adaptation.) The postexposure measures of eye-foot coordination (right foot) and of eye-hand coordination with the left and right arm were then taken. Eye-foot coordination was tested first upon termination of exposure; the order of the arm tested first was counterbalanced.

\section{RESULTS}

The results for Experiment 1 are shown in Tables 1 and 2 , and those for Experiment 2 are shown in Table 3. The numbers refer to differences between the centroids of the pre- and postexposure markings in degrees of visual angle.

The presence of interpedal transfer is clearly seen following base-left prism viewing (Table 1): The changes in eye-foot coordination with both the exposed and unexposed limbs are statistically equivalent. Viewing through base-left prisms produces significantly larger shifts than viewing through base-right prisms $(\mathrm{p}<.05$, $t$ test). Results of the base-right prism viewing conditions also produce equal mean changes with both the exposed and unexposed limbs. However, a finer analysis (Table 2) shows some puzzling discrepancies: transfer to the unexposed leg is very large after exposure of the left leg but is absent after exposure of the right leg, even though the effects on the exposed leg itself are the same in both cases. Data in Table 3 clearly indicate that shifts in eye-hand coordination occur not only in responses with the arm
Table 1

Changes in Eye-Foot Coordination Following $50 \mathrm{M}$ in of Base Left Prism Rearrangement (in Degrees of Visual Angle)

\begin{tabular}{|c|c|c|c|c|}
\hline & $\begin{array}{c}\text { Exposed } \\
\text { Limb }\end{array}$ & $\begin{array}{l}\text { Unexposed } \\
\text { Limb }\end{array}$ & $\begin{array}{l}\text { Exposed } \\
\text { Limb }\end{array}$ & $\begin{array}{l}\text { Unexposed } \\
\text { Limb }\end{array}$ \\
\hline Ss & Left Foot & Right Foot & Right Foot & Left Foot \\
\hline 1 & 3.9 & 4.9 & 1.3 & 1.8 \\
\hline 2 & 7.9 & 3.6 & 10.0 & 10.0 \\
\hline 3 & 6.1 & 3.8 & 8.6 & 7.2 \\
\hline 4 & 4.1 & 2.5 & 7.2 & 6.3 \\
\hline 5 & 5.6 & 4.5 & 4.7 & 5.2 \\
\hline 6 & 7.4 & 4.7 & 5.4 & 3.2 \\
\hline Means & 5.8 & 4.0 & 6.2 & 5.6 \\
\hline$p$ (t test) & $<0.001$ & $<0.001$ & $<0.01$ & $<0.01$ \\
\hline
\end{tabular}

Table 2

Changes in Eye-Foot Coordination Following $50 \mathrm{M}$ in of Base Right Prism Rearrangement (in Degrees of Visual Angle)

\begin{tabular}{|c|c|c|c|c|}
\hline & $\begin{array}{c}\text { Exposed } \\
\text { Limb }\end{array}$ & $\begin{array}{l}\text { Unexposed } \\
\text { Limb }\end{array}$ & $\begin{array}{c}\text { Exposed } \\
\text { Limb }\end{array}$ & $\begin{array}{l}\text { Unexposed } \\
\text { Limb }\end{array}$ \\
\hline Ss & Left Foot & Right Foot & Right Foot & Left Foot \\
\hline 7 & 1.8 & 2.2 & 2.3 & -0.7 \\
\hline 8 & 1.3 & 2.2 & 2.5 & -1.0 \\
\hline 9 & 3.9 & 7.0 & 2.7 & 1.0 \\
\hline 10 & 2.2 & 5.6 & 4.1 & -0.7 \\
\hline 11 & 2.7 & 6.3 & 1.3 & -2.2 \\
\hline 12 & 1.6 & 5.4 & 1.8 & 2.7 \\
\hline Means & 2.3 & 4.7 & 2.5 & -0.2 \\
\hline$p$ (t test) & $<0.01$ & $<0.01$ & $<0.01$ & n.s. \\
\hline
\end{tabular}


ipsilateral to the leg viewed through prisms, but also in responses of the contralateral arm. These data are consistent with the hypothesis that viewing leg movements through prisms produces generalized adaptation. DISCUSSION

Self-produced movements of one leg viewed through displacing prisms were shown to produce adaptive changes in both legs and both arms. These findings are generally consistent with previous findings (Hamilton, 1964b; Mikaelian, 1970) and with the assumption that prism-displaced feedback from leg movements produces generalized adaptation, in contrast with the restricted adaptation found with feedback only from arm movements. This difference may be related to the functional coupling between the limbs and the body: leg movements are linked to gross body locomotion and commonly transport the body through space, while arm movements are essentially manipulatory and mostly unrelated to locomotion. In addition, leg movements typically occur in concert, while arm movements are substantially independent of each other.

The present experiment does not provide any information about the nature of the generalized adaptation. Any of several interpretations would be equally compatible with these findings, e.g., remapping of directed limb movements on directions of the head (Efstathiou et al, 1967; Mikaelian, 1970), changes in visual perception (Rock, 1966; Festinger et al, 1967), or changes in position
Table 3

Changes in Sensorimotor Coordinations Following $30 \mathrm{M}$ in of Base Left Prism Rearrangement (in Degrees of Visual Angle)

\begin{tabular}{|c|c|c|c|}
\hline \multirow[b]{3}{*}{ Ss } & \multicolumn{3}{|c|}{ Sensorimotor Changes } \\
\hline & $\begin{array}{l}\text { Eye-Foot } \\
\text { Coordi- } \\
\text { nation }\end{array}$ & $\begin{array}{l}\text { Eye-Hand } \\
\text { Coordi- } \\
\text { nation }\end{array}$ & $\begin{array}{l}\text { Eye-Hand } \\
\text { Coordi- } \\
\text { nation }\end{array}$ \\
\hline & $\begin{array}{c}\text { Exposed } \\
\text { Leg }\end{array}$ & $\begin{array}{l}\text { Ipsi- } \\
\text { lateral } \\
\text { Arm }\end{array}$ & $\begin{array}{l}\text { Contra- } \\
\text { lateral } \\
\text { Arm }\end{array}$ \\
\hline 1 & 4.5 & 3.7 & -8.0 \\
\hline 2 & 4.7 & 7.7 & 7.1 \\
\hline 3 & 9.5 & 10.0 & 6.6 \\
\hline 4 & 5.4 & 10.0 & 8.5 \\
\hline 5 & 4.7 & 10.0 & 7.1 \\
\hline 6 & 10.0 & 10.0 & 6.0 \\
\hline 7 & 4.5 & 3.0 & 6.4 \\
\hline 8 & 4.7 & 3.7 & 4.7 \\
\hline Means & 6.0 & 7.3 & 4.8 \\
\hline $\mathrm{p}^{*}$ & $<0.001$ & $<0.001$ & $<0.05$ \\
\hline
\end{tabular}

*t test

sense of the head or eyes (Hamilton, 1964a; Harris, 1965). Further work is needed to isolate alternative predictions of each of these theories.

Although these findings generally agree with those of Hamilton (1964b), the present experiments found a considerably greater percentage of transfer to the unexposed leg and to both arms than did Hamilton. If the aftereffect measured with each limb represents the sum of generalized adaptation and adaptation restricted to that limb, as several authors have proposed, the discrepancies between Hamilton's findings and the present ones may be ascribed to a larger proportion of general adaptation in the present experiments, although it is not yet possible to specify the procedural differences responsible.

REFERENCES

EFSTATHIOU, A., BAUER, J., GREENE, M., \& HELD, R. Altered reaching following adaptation to optical displacement of the hand. Journal of Experimental Psychology, 1967, 73, 113-120.

FESTINGER, L., ONO, H., BURNHAM, C. A., \& BAMBER, D. Efference and the conscious experience of perception. Journal of Experimental Psychology, $1967,74(4$, Part 2 of No. 637).

HAMILTON, C. R. Studies on adaptation to deflection of the visual field in split-brain monkeys and man. Doctoral dissertation, California Institute of Technology. Ann Arbor, Mich: University Microfilms, 1964a, No. 64-11, 398.

HAMILTON, C. R. Intermanual transfer of adaptation to prisms. American Joumal of Psychology, 1964b, 77, 457-462.

HARRIS, C. S. Adaptation to displaced vision. A proprioceptive change. Doctoral dissertation, Harvard University. Ann Arbor, Mich: University Microfilms, 1963, No. 63-8162.

HARRIS, C. S. Perceptual adaptation to inverted, reversed, and displaced vision. Psy chological Review, 1965, 72, 419-444.

HELD, R., \& GOTTLIEB, N. Technique for studying adaptation to disarranged eye-hand coordination. Perceptual \& Motor Skills, $1958,8,83-86$.

MIKAELIAN, H. H, Failure of bilateral transfer in modified eye-hand coordination. Paper presented at the meeting of the Eastern Psychological Association, New Y ork, 1963.

MIKAELIAN, H. H. Adaptation to rearranged eye-foot coordination. Perception \& Psychophysics, 1970,8 222-224.

ROCK, I. The nature of perceptual adaptation. New York: Basic Books, 1966.

*This study was supported by NIH Grant No. MH14148-01. 